\title{
Anticoagulation Resumption After Intracerebral Hemorrhage
}

\author{
Yan-guang Li ${ }^{1,2}$. Gregory Y. H. Lip ${ }^{1,2,3}$
}

Published online: 21 May 2018

(C) The Author(s) 2018

\begin{abstract}
Purpose of review Decision-making on resuming oral anticoagulant (OAC) after intracerebral hemorrhage (ICH) evokes significant debate among clinicians. Such patients have been excluded from randomized clinical trials. This review article provides a comprehensive summary of the evidence on anticoagulation resumption after ICH.

Recent findings $\mathrm{OAC}$ resumption does not increase the risk of recurrent $\mathrm{ICH}$ and can also reduce the risk of all-cause mortality. OAC cessation exposes patients to a significantly higher risk of thromboembolism, which could be reduced by resumption. The optimal timing of anticoagulation resumption after ICH is still unknown. Both early $(<2$ weeks) and late ( $>4$ weeks) resumption should be reached only after very careful assessment of risks for ICH recurrence and thromboembolism. The introduction of new oral anticoagulants and other interventions, such as left atrial appendage closure, has provided some patients with more alternatives.

Summary Given the lack of high-quality evidence to guide clinical decision-making, clinicians must carefully balance the risks of thromboembolism and recurrent ICH in individual patients. We propose a management approach which would facilitate the decision-making process on whether anticoagulation is appropriate, as well as when and how to restart anticoagulation after ICH.
\end{abstract}

Keywords Intracerebral hemorrhage $\cdot$ Anticoagulation $\cdot$ Resumption $\cdot$ Warfarin $\cdot$ Non-vitamin K antagonist oral anticoagulants

\section{Introduction}

Intracerebral hemorrhage (ICH) is associated with a high risk of mortality and stroke, as well as recurrent ICH [1•]. Of note, ICH is also the most devastating adverse event in patients receiving oral anticoagulants (OAC) [2]. Among patients on anticoagulation, the annual incidence of $\mathrm{ICH}$ varies between 0.6 and $1.0 \%$ [3]. Indeed, anticoagulation-related ICH is more severe and associated with more extensive hemorrhage and higher mortality rate, compared with spontaneous ICH [4].

This article is part Topical Collection on Cardiovascular Disease and Stroke

Gregory Y. H. Lip

g.y.h.lip@bham.ac.uk

1 Institute of Cardiovascular Sciences, University of Birmingham, Birmingham, England, UK

2 Department of Cardiology, Chinese PLA Medical School, Beijing, China

3 Aalborg Thrombosis Research Unit, Department of Clinical Medicine, Aalborg University, Aalborg, Denmark
Anticoagulation is supported by Class I guidelines for patients with atrial fibrillation (AF) and high risk of ischemic stroke (IS) and systemic embolism (SE), mechanical prosthetic valves, or those at high risk of deep venous thrombosis (DVT) and pulmonary embolism (PE). Decision-making on resuming anticoagulation after ICH evokes significant debate among clinicians. Such patients have been excluded from randomized clinical trials of stroke prevention in AF. As with decision-making with anticoagulation therapy in any patient, carefully balancing the risks of thromboembolism and bleeding, especially the risk of recurrent $\mathrm{ICH}$, is the primary concern when making this decision in patients who have experienced a recent ICH [5]. The lack of high-quality evidence, however, makes the decision-making challenging for clinicians and quite variable in practice [6].

At a simplistic level, we propose three steps to make such a decision (Fig. 1): first, evaluate the individual's risk of thromboembolism and hemorrhage [7]; second, choose the optimal anticoagulant and appropriate timing to reinitiate anticoagulation [8]; and third, reduce the risk of recurrent hemorrhage through controlling modifiable risk factors, such as uncontrolled hypertension, anemia, renal dysfunction, diabetes, and heart failure (HF) $[9,10]$. 


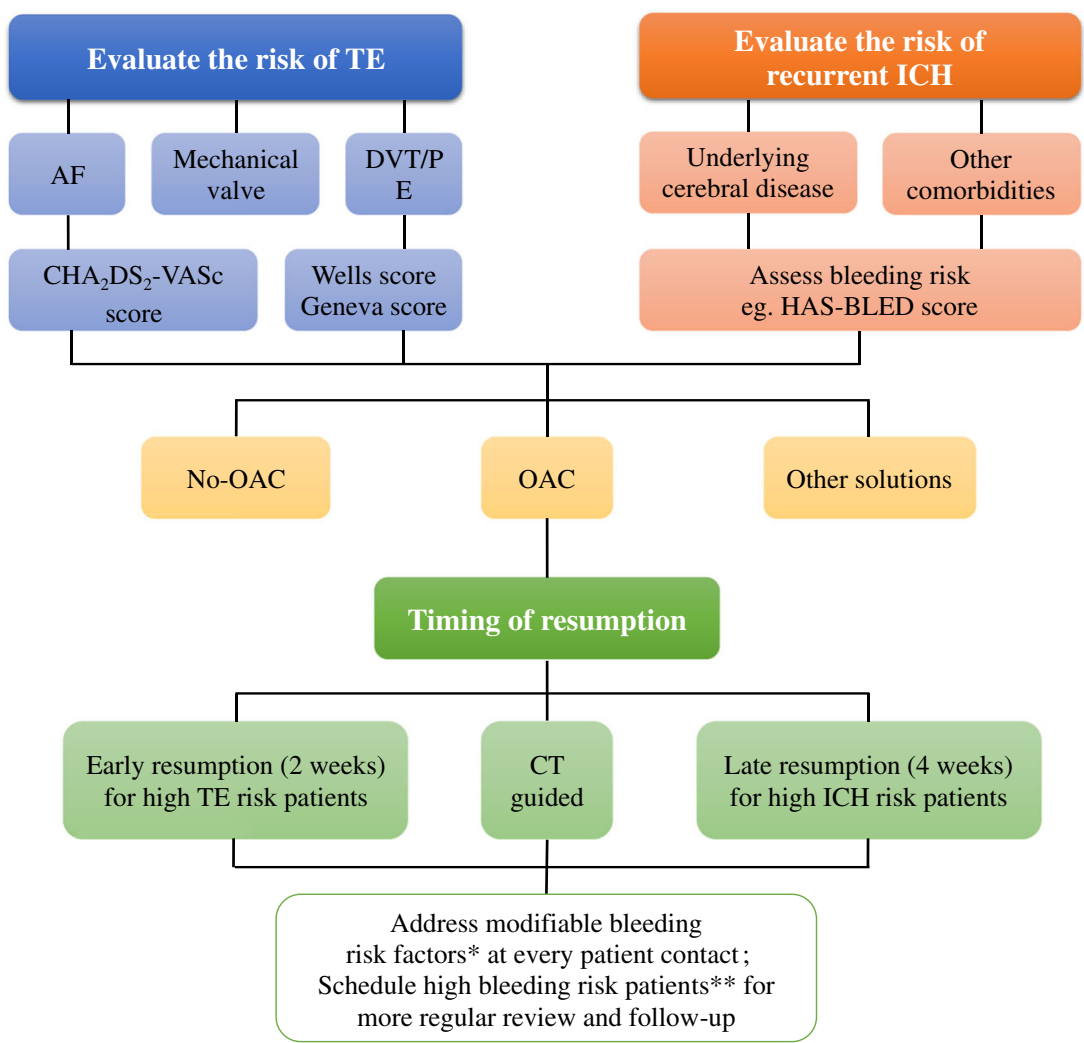

Fig. 1 Flowchart of decision-making regarding OAC resumption in patients with recent $\mathrm{ICH}$. $\mathrm{AF}=$ atrial fibrillation; $\mathrm{CT}=$ computed tomography; $\mathrm{CHA}_{2} \mathrm{DS}_{2}$-VASc = congestive heart failure, hypertension, age $\geq 75$ years, type 2 diabetes, previous stroke/transient ischemic attack/ thromboembolism, vascular disease, age 65 74 years, and gender category; DVT = deep venous thrombosis; HAS-BLED = hypertension, abnormal renal/liver function, stroke, bleeding history or predisposition,

Nevertheless, this approach towards decision-making could also be difficult in clinical practice, because of the lack of risk evaluation tools for complicated clinical conditions, the insufficient evidence from the randomized clinical trials, and the existence of shared risk factors for both thromboembolism and hemorrhage.

This review article aims to provide an up-to-date overview regarding the pros and cons of restarting anticoagulation after ICH. We also propose a management approach which would facilitate the decision-making process on whether anticoagulation is appropriate, as well as when and how to restart anticoagulation after ICH.

\section{The Risks of Recurrent ICH, Thromboembolism, and Mortality}

Current guidelines recommended that the decision on restarting OAC should be taken by a multidisciplinary team of stroke physicians, neurologists, cardiologists, neuroradiologists, and neurosurgeons [11]. This decision mainly depends on an individual's risk of recurrent ICH versus risk of labile international normalized ratio (INR), elderly, drugs/alcohol concomitantly; ICH, intracerebral hemorrhage; OAC, oral anticoagulant; $\mathrm{PE}=$ pulmonary embolism; $\mathrm{TE}=$ thromboembolism. $\mathrm{A}$ single asterisk indicates modifiable bleeding risk factors that include uncontrolled blood pressure, labile INRs (if on warfarin), concomitant aspirin/NSAID use, alcohol excess. Double asterisks indicate high risk patients can be defined as HAS-BLED score $\geq 3$

thromboembolism. The relative risk of mortality is also a major concern.

\section{Risk of Recurrent ICH After OAC Resumption}

In non-anticoagulated patients with a history of ICH, the 1year risk of recurrent ICH ranges from 0 to $8.6 \%$ [12]. In patients resuming $\mathrm{OAC}$, this number ranges from 2.5 to $8 \%$ [12]. For example, in one multicenter study $(n=267)$, warfarin resumption was associated with an annual ICH recurrence rate of $2.56 \%$ [13]. Whether OAC resumption per se truly increases the risk of recurrent ICH is still debatable, given the many associated comorbidities related to ICH recurrence.

The majority of studies demonstrate that OAC resumption did not increase the risk of recurrent ICH [14, 15••, 16-19] (see Table 1). In one retrospective cohort study $(n=160)$, recurrent ICH occurred with higher frequency after OAC resumption, but this was statistically nonsignificant compared with patients who did not resume OAC (7.6 vs. $3.7 \%, p=$ 0.48) [14]. Also, OAC resumption did not increase the risk of ICH in a Danish nationwide cohort study [15••]. In another large observational cohort $(n=2415)$, warfarin resumption 
after incident ICH was associated with similar risk of recurrent ICH to non-resumption of warfarin [17••]. These results were confirmed by a recent systematic review and meta-analysis, including eight studies and $5306 \mathrm{ICH}$ patients, in which reinstatement of OAC had a similar risk of recurrent ICH to nonOAC restarters [18].

Nevertheless, some contradictory results exist. For example, a retrospective study $(n=428)$ showed that OAC restarting increased the risk of major bleeding (5.5 vs. 3.1 per 100 patient-years, $p=0.024$ ), and recurrent ICH was observed only in patients with OAC use [20]. Different study designs and selection biases may explain the contradictory results. In many studies, only the patients with "less severe" $\mathrm{ICH}$, that is ICH with smaller volume of hemorrhage and mild functional changes, could have received OAC resumption, hence leading to a lower recurrent ICH risk [21, 22].

For clinical practice, different patient profiles may lead to a varying risk of ICH recurrence, and therefore, individualized evaluation is critical [23]. We suggest that risk factors for recurrent ICH should be considered before deciding OAC resumption [24, 25]. Currently, there are some wellidentified risk factors for recurrent ICH (Table 2). For example, the location of ICH is a significant risk factor. Lobar hemorrhage has a higher ICH recurrent rate compared with hemorrhage in a deep cortical location (22 vs. $4 \%$ for cumulative 2-year rate, $p=0.007$ ) [26].

In postoperative (neurosurgery for $\mathrm{ICH}$ ) patients with spontaneous ICH, diabetes mellitus (odds ratio [OR], 2.72; 95\% CI, 1.01-7.35) has been related to recurrent ICH [27]. In other studies, patients with hepatic $\mathrm{C}$ virus infection had increased risk of ICH (HR, 1.60; 95\% CI, 1.24-2.06) [28], as has severe hypertension (systolic blood pressure $\geq 160 \mathrm{mmHg}$ or diastolic blood pressure $\geq 110 \mathrm{mmHg}$ ), which was associated with a sixfold increased risk of ICH [29]. In addition, patients with recent intracranial microbleeds had substantial risk of incident ICH [30]. Leukoaraiosis was also related with high risk of significant ICH (relative risk [RR], 1.65; 95\% CI, 1.26-2.16) [31]. For these two risk factors, brain imaging evidence provided by computed tomography (CT) or magnetic resonance imaging (MRI) is required.

Ethnicity is also a major risk factor for ICH. Asian populations had higher risk of ICH in the major trials of the nonVKA oral anticoagulants (NOACs) [32-35]. For example, in the RE-LY (Randomized Evaluation of Long-term Anticoagulant Therapy) trial, Asian populations had higher risk of $\mathrm{ICH}$ in both of the warfarin (1.10 vs. $0.71 \%$ year) and dabigatran ( 0.45 vs. $0.29 \% /$ year) arms compared with non-Asian populations [35]. Further, the East Asian population had over twofold risk of ICH compared with non-East Asian ones in the ARISTOTLE (Apixaban for Reduction in Stroke and Other Thromboembolic Events in Atrial Fibrillation) trial (warfarin, 1.88 vs. $0.67 \% / y e a r ; ~ a p i x a b a n$, 0.67 vs. $0.30 \% /$ year) [33]. 


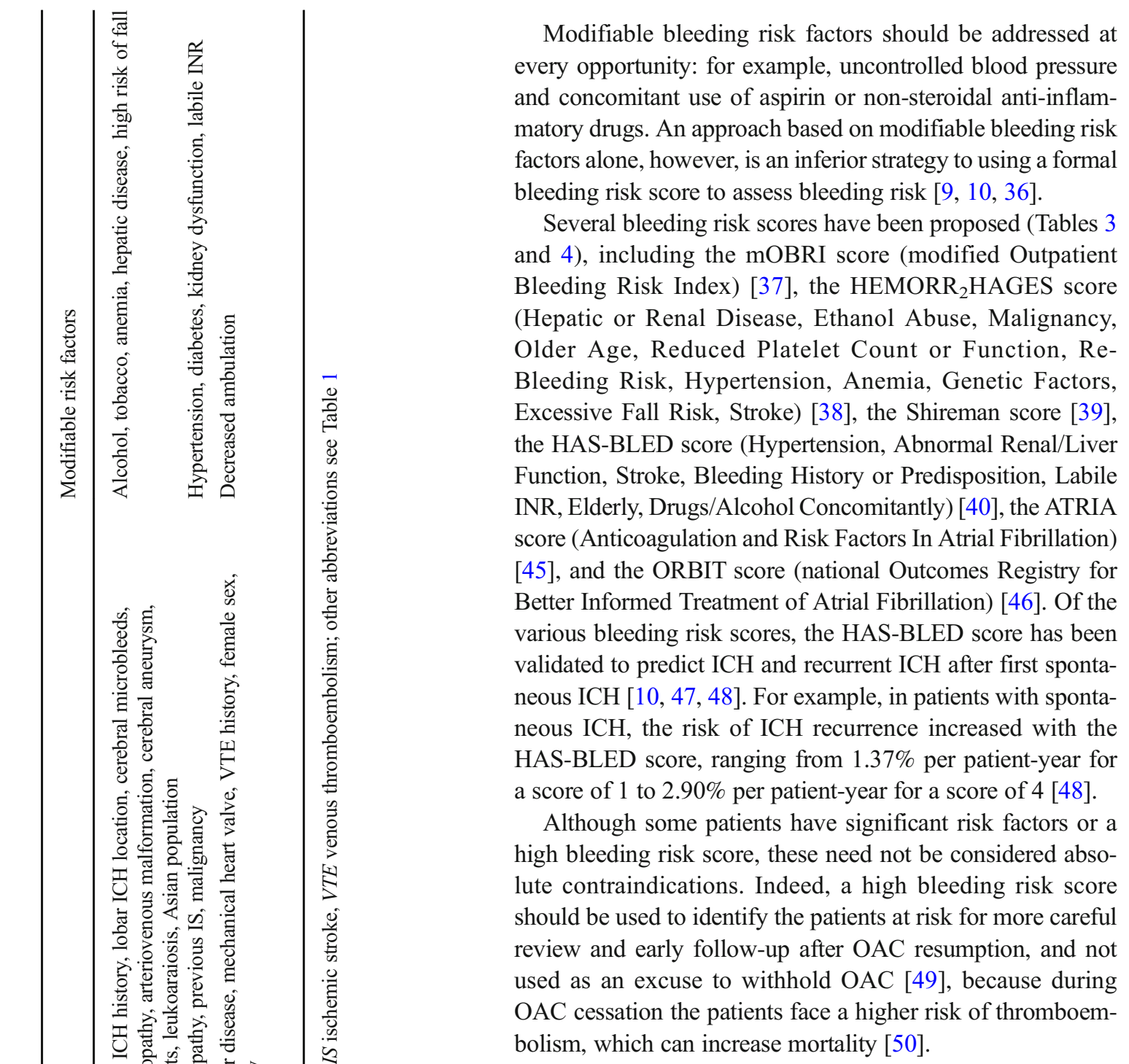

Risk of Thromboembolism During OAC Cessation

OAC resumption is important for the patients at high risk of thromboembolism, such as those with prosthetic mechanical valve, high risk of $\mathrm{PE}$, and $\mathrm{AF}$ patients with a high $\mathrm{CHA}_{2} \mathrm{DS}_{2}-$ VASc score (congestive HF, hypertension, age $\geq 75$ years, type 2 diabetes, previous stroke/TIA/thromboembolism, vascular disease, age 65 74 years, and gender category), i.e., $\mathrm{CHA}_{2} \mathrm{DS}_{2}$-VASc score $\geq 4$. In a recent systematic review and meta-analysis of restarting $\mathrm{OAC}$ after $\mathrm{ICH}, \mathrm{AF}$ is the most common reason for anticoagulation (34.7-77.8\%), followed by prosthetic heart valve (2.6-27.8\%), venous thromboembolism (7.9-20.8\%), and previous IS (3.7-71.8\%) [18]. In other studies, the most common reason for OAC resumption after ICH was mechanical heart valve $(39-68 \%)[14,16]$. Undoubtedly, the prolonged cessation of OAC after ICH would expose these high-risk patients to a greater risk of thromboembolism. 
For example, the risk of major thromboembolism among patients $(n=13,000)$ with prosthetic heart valves and not on OAC was 4.0 per 100 patient-years (95\% CI, 2.9-5.2) [51]. Mitral valve prosthesis is associated with a fivefold higher incidence of valve thrombosis and 1.5 times greater incidence of thromboembolism [52]. The combination of double mechanical prosthesis was related to an even higher risk of thromboembolism (91\%) [12]. Also, the risk of DVT was 2 to $15 \%$ in patients with recent ICH [53]. PE occurs in 1 to $5 \%$ of recent ICH patients in which anticoagulation was stopped [12]. Given the high risk of recurrent venous thromboembolism, these patients may require antithrombotic therapy despite the risk of recurrent $\mathrm{ICH}$.

OAC resumption can reduce the risk of thromboembolism. For example, a retrospective study demonstrated that OAC in AF patients after ICH was associated with a significantly reduced incidence of thromboembolism (RR, 0.19; 95\% CI, $0.11-0.54)$ [20]. In a nationwide cohort $(n=2415)$, warfarin resumption had a lower rate of IS and SE in AF patients with hemorrhagic stroke (HR, 0.49; 95\% CI, 0.24-1.02) [17••]. In a Danish cohort $(n=1725)$, the patients with OAC resumption were associated with 41 to $54 \%$ lower risk of IS/SE and allcause mortality, compared with no OAC treatment $[15 \bullet \cdot]$. These results were also confirmed in the Danish nationwide registries $(n=6369)$ (HR, 0.58 ; 95\% CI, 0.35-0.97) [1 $]$, another Danish study (HR, $0.55 ; 95 \%, 0.39-0.78)[15 \cdot 0]$ and in a German cohort (5.2 vs. $15 \%$ per 100 patient-years, $p<0.001$ ) [16]. In a recent meta-analysis about OAC resumption after $\mathrm{ICH}$, reinitiation of OAC resulted in a significantly lower risk of thromboembolic complications (HR, 0.34; 95\% CI, 0.250.45) [18]. Also, the MUCH-Italy study (Multicentre Study on Cerebral Hemorrhage in Italy) showed an $81 \%$ reduced risk of thromboembolism among patients restarted $\mathrm{OAC}$ after $\mathrm{ICH}$ [19].

Despite the high risk of thromboembolism and the efficiency of anticoagulation, a large proportion of ICH survivors often do not resume OAC $[1 \bullet, 15 \bullet, 54,55]$. Although some prior studies suggest that OAC could be discontinued safely for a certain period without significant high risk of thromboembolism, the duration of this period is less certain [41]. For example, in the REVERSE-AD study (Reversal Effects of Idarucizumab on Active Dabigatran), the majority of the thrombotic events occurred in patients who had not resumed $\mathrm{OAC}$ in the first 30 days after ICH [42]. Thus, although immediate OAC resumption is not appropriate for most patients, the duration of withholding OAC should be carefully considered and balanced against the risk of recurrent thromboembolism.

There are some well-identified risk factors for thromboembolism (see Table 2), and several risk scoring systems have been proposed to evaluate the individual's risk of thromboembolism, such as the $\mathrm{CHADS}_{2}$ [43] and $\mathrm{CHA}_{2} \mathrm{DS}_{2}$-VASc scores in AF [44], and the modified Wells score [56] and the 
revised Geneva score in venous thromboembolism [57] (Table 4). Identifying these risk factors and risk score would be useful to predict the individuals' risk of thromboembolism.

\section{OAC Resumption and Risk of Mortality}

The 1-year risk of mortality in patients with $\mathrm{ICH}$ who restarted OAC ranges from 2.5 to $48 \%$ (Table 1). Previous studies demonstrated that OAC resumption after ICH had significantly lower risk of death $[1 \bullet, 16]$. In a large Danish observational study, warfarin resumption reduced the rate of mortality in patients with hemorrhagic stroke (Table 1) [17••]. More recently, the MUCH study showed a reduced mortality rate in patients with warfarin resumption compared with those not on OAC [19]. While OAC resumption in patients with lobar ICH is associated with higher risk of recurrent $\mathrm{ICH}$, it is also associated with decreased mortality (HR, 0.29 ; 95\% CI, $0.17-$ $0.45)$ [58].

\section{Timing of Restarting OAC}

In patients who require $\mathrm{OAC}$ after the acute period of $\mathrm{ICH}$, it is important to choose the right timing for restarting OAC. The opinion about the timing of reinitiating $\mathrm{OAC}$ (warfarin) ranges from 3 days to 30 weeks [59]. In a Japanese survey, for example, $28 \%$ patients restarted OAC within the first week, 25\% during the second week, $28 \%$ between 3 or 4 weeks, and $18 \%$ after 4 weeks [60].

In the Danish nationwide cohort $(n=1725)$, OAC was restarted at $2-10$ weeks after ICH $[15 \bullet \cdot]$. Other evidence supports that $\mathrm{OAC}$ can be restarted 4-8 weeks after ICH if the cause of ICH has been treated [61]. Also, restarting OAC at 4 weeks after ICH was associated with 42 to $59 \%$ lower risk of recurrent ICH $[15 \bullet \cdot]$. In a multicenter retrospective study in Germany $(n=719)$, anticoagulation was restarted at median of 31 days, and these patients had fewer ischemic complications (5.2 vs. $15.0 \%, p<0.001$ ), decreased risk of unfavorable functional outcome (RR, 0.55; 95\% CI, 0.39-0.78), and similar hemorrhagic complications ( 8.1 vs. $6.6 \%, p=0.48)$, compared with no OAC resumption [16]. Another study also demonstrated that $\mathrm{OAC}$ resumption at 2 weeks after ICH seemed reasonable, resulting in less clinical events including thromboembolism event [20].

Although heparin or OAC may probably be safe to be restarted after day 7 post-ICH, without increasing the risk of ICH [62], any early OAC resumption $(<2$ weeks) should be cautiously considered. An observational study demonstrated that early OAC resumption ( $<2$ weeks) could not improve the composite outcome (i.e., thromboembolic events, major bleeding events, and all-cause mortality), particularly because of an increased risk of major bleeding events [20]. Given these risks, some researchers have suggested that OAC should be 
avoided in the first 2 weeks after OAC-associated parenchymal ICH and resumption at 4 weeks if the cause of ICH has been amended or in patients with small ICH and high thromboembolic risk [63].

Hence, the timing of OAC restarting depends on individual clinical condition (i.e., the risks of thromboembolism and likelihood of recurrent ICH). For example, in patients with brainstem or cerebellar ICH, the timing should be delayed at least $8-10$ weeks after the event [63]. On the other hand, in patients with prosthetic mechanical valves, who have a (very) high risk of thromboembolism, OAC is suggested to be resumed at 2 weeks after the onset of ICH or sooner if the hemorrhage burden is small and causative mechanism treated or stabilized.

When considering the timing of restarting anticoagulation, a brain CT scan and MRI can help to confirm the resolution of ICH [64]. Restarting OAC without the confirmation of ICH resolution has been related to increased composite outcome (i.e., thromboembolic events, major bleeding events, and allcause mortality) in a retrospective study (RR, 4.40; 95\% CI, 1.02-19.04) [20]. Nevertheless, selection bias such that subjects with less severe ICH often restart OAC earlier than severe ones, may have led to these findings of better outcomes.

\section{The Choice of Anticoagulant}

Currently, we have a number of anticoagulants that are approved for use for atrial fibrillation and PE/DVT. The vitamin $\mathrm{K}$ antagonists (VKAs) are widely used in patients with $\mathrm{AF}$, mechanical/prosthesis heart valve, and DVT. In patients with prosthetic mechanical valves, the VKAs are the only choice for anticoagulation [65]. For AF patients, VKAs have been associated with a $64 \%$ reduced risk of stroke and $26 \%$ reduction in all-cause mortality, compared to control or placebo; however, VKAs use is also associated with a higher risk of ICH [66].

With the introduction of NOACs, which are associated with a significantly lower risk of $\mathrm{ICH}$, the risk of anticoagulation-related $\mathrm{ICH}$ is perhaps decreasing compared to the VKA era [67]. The NOACs could be an optimal choice when considering anticoagulation resumption in patients with $\mathrm{AF}$ and incident ICH. Also, NOAC-related ICH seems to be less severe than that of warfarin, with smaller hematoma volumes, less hematoma expansion, and lower risk of poor functional outcome or death $[68,69]$.

The availability of reversal agents for the NOACs also is a consideration when using these drugs, given the possibility of rapid anticoagulation reversal in patients with incident $\mathrm{ICH}$. However, the evidence of NOACs in patients with $\mathrm{AF}$ and recent ICH remains limited. Given the significantly lower risk of ICH in AF patients [61], the role of NOACs in these patients could be promising. In patients at high risk of DVT and $\mathrm{PE}, \mathrm{NOACs}$ may also be an alternative to warfarin [70-75].
Heparin is also widely used as a temporary parenteral anticoagulant. One previous study demonstrated that low-dose heparin treatment after $48 \mathrm{~h}$ of onset in ICH patients was not associated with an increased hematoma growth and should be used for DVT and PE prophylaxis [76].

\section{Reducing the Risk of Recurrent ICH After Restarting OAC}

After restarting OAC, the risk of $\mathrm{ICH}$ recurrence can be reduced through controlling those modifiable bleeding risk factors (Table 2) [77]. In patients in whom OAC resumption is not an option, left atrial appendage occlusion in patients with $\mathrm{AF}$ and the intra-venous filter in patients with DVT and $\mathrm{PE}$ are reasonable alternatives to reduce thromboembolic risk [78].

In patients treated with warfarin, well-controlled international normalized range (INR) was related to less major bleeding and thromboembolism compared with those without OAC $(p<0.01$, respectively) [20]. Thus, in patients with mechanical prosthetic valves, for which only warfarin could be used, time in therapeutic range (ideally $>70 \%$ ) is important. A lower target INR should not be encouraged, which is related to higher risk of thromboembolism in comparison to the guideline-recommended INR ranges [79].

\section{Conclusion}

Given the observational nature of the studies regarding OAC resumption after $\mathrm{ICH}$, there is uncertainty regarding resumption of OAC therapy and its timing. The limited high-quality evidence regarding this issue leads to limited evidence-based guidelines and inconsistency in clinical practice. There are randomized clinical trials ongoing, which may provide more information in the future [80]. For example, the APACHE-AF (Apixaban versus Antiplatelet drugs or no antithrombotic drugs after anticoagulation-associated intraCerebral HaEmorrhage in patient with Atrial Fibrillation) trial is a phase II, multicenter, randomized clinical trial, aiming to evaluate the risk of IS and recurrent ICH for patients restarted with anticoagulation [80]. This plans to include $100 \mathrm{AF}$ patients with a history of recent $\mathrm{ICH}$ randomly assigned in a 1:1 ratio to apixaban or control [80]. The SoSTART (Start or Stop Anticoagulants Randomised Trial) trial is a multicenter, randomized, open, interventional trial, aiming to recruit 800 participants. This trial aims to test whether restarting full treatment dose $\mathrm{OAC}$ would result in a beneficial net reduction of all serious vascular events compared with not starting OAC [81]. 


\section{Compliance with Ethical Standards}

Conflict of Interest Yan-guang Li and Gregory Y.H. Lip declare no conflict of interest.

Human and Animal Rights and Informed Consent This article does not contain any studies with human or animal subjects performed by any of the authors.

Open Access This article is distributed under the terms of the Creative Commons Attribution 4.0 International License (http:// creativecommons.org/licenses/by/4.0/), which permits unrestricted use, distribution, and reproduction in any medium, provided you give appropriate credit to the original author(s) and the source, provide a link to the Creative Commons license, and indicate if changes were made.

\section{References}

Papers of particular interest, published recently, have been highlighted as:

- Of importance

•- Of major importance

1. Ottosen TP, Grijota M, Hansen ML, et al. Use of antithrombotic therapy and long-term clinical outcome among patients surviving intracerebral hemorrhage. Stroke. 2016;47(7):1837-43. A good population-based cohort study illustrated the long-term benefits of anticoagulation among patients surviving intracerebral hemorrhage.

2. Purrucker JC, Haas K, Rizos T, Khan S, Wolf M, Hennerici MG, et al. Early clinical and radiological course, management, and outcome of intracerebral hemorrhage related to new oral anticoagulants. JAMA Neurol. 2016;73(2):169-77.

3. Lansberg MG, O'Donnell MJ, Khatri P, Lang ES, Nguyen-Huynh $\mathrm{MN}$, Schwartz NE, et al. Antithrombotic and thrombolytic therapy for ischemic stroke: antithrombotic therapy and prevention of thrombosis, 9th ed: American College of Chest Physicians Evidence-Based Clinical Practice Guidelines. Chest. 2012;141(2 Suppl):e601S-36S.

4. Liotta EM, Prabhakaran S. Warfarin-associated intracerebral hemorrhage is increasing in prevalence in the United States. J Stroke Cerebrovasc Dis. 2013;22(7):1151-5.

5. Kittelson JM, Steg PG, Halperin JL, Goldenberg NA, Schulman S, Spyropoulos AC, et al. Bivariate evaluation of thromboembolism and bleeding in clinical trials of anticoagulants in patients with atrial fibrillation. Thromb Haemost. 2016;116(3):544-53.

6. Zazulia A. Antiplatelet and anticoagulant therapy after intracerebral hemorrhage. Neurol Clin. 2015;33(2):329-45.

7. Lip G, Freedman B, De Caterina R, Potpara TS. Stroke prevention in atrial fibrillation: past, present and future. Comparing the guidelines and practical decision-making. Thromb Haemost. 2017;117(7):1230-9.

8. Paciaroni M, Agnelli G, Ageno W, Caso V. Timing of anticoagulation therapy in patients with acute ischaemic stroke and atrial fibrillation. Thromb Haemost. 2016;116(3):410-6.

9. Esteve-Pastor MA, Rivera-Caravaca JM, Shantsila A, Roldan V, Lip GYH, Marin F. Assessing bleeding risk in atrial fibrillation patients: comparing a bleeding risk score based only on modifiable bleeding risk factors against the HAS-BLED score. The AMADEUS Trial. Thromb Haemost. 2017;117(12):2261-6.
10. Guo Y, Zhu H, Chen Y, Lip GYH. Comparing bleeding risk assessment focused on modifiable risk factors only versus validated bleeding risk scores in atrial fibrillation. Am J Med. 2018;131(2): 185-92.

11. Kirchhof P, Benussi S, Kotecha D, Ahlsson A, Atar D, Casadei B, et al. ESC guidelines for the management of atrial fibrillation developed in collaboration with EACTS. Europace: European pacing, arrhythmias, and cardiac electrophysiology: journal of the working groups on cardiac pacing, arrhythmias, and cardiac cellular electrophysiology of the European Society of Cardiology 2016. 2016;18(11):1609-78.

12. Giakoumettis D, Alexiou GA, Vrachatis DA, Themistoklis K, Stathis P, Vavuranakis M, et al. Antithrombotic treatment management in patients with intracerebral hemorrhage: reversal and restart. Curr Pharm Des. 2017;23(9):1392-405.

13. Poli D, Antonucci E, Dentali F, Erba N, Testa S, Tiraferri E, et al. Recurrence of ICH after resumption of anticoagulation with VK antagonists: CHIRONE study. Neurology. 2014;82(12):1020-6.

14. Witt DM, Clark NP, Martinez K, Schroeder A, Garcia D, Crowther MA, et al. Risk of thromboembolism, recurrent hemorrhage, and death after warfarin therapy interruption for intracranial hemorrhage. Thromb Res. 2015;136(5):1040-4.

15.• Nielsen PB, Larsen TB, Skjoth F, Gorst-Rasmussen A, Rasmussen LH, Lip GY. Restarting anticoagulant treatment after intracranial hemorrhage in patients with atrial fibrillation and the impact on recurrent stroke, mortality, and bleeding: a nationwide cohort study. Circulation. 2015;132(6):517-25. A very good nationwide registry study demonstrated the benefit of anticoagulation reinitiation in patients with atrial fibrillation and intracranial hemorrhage.

16. Kuramatsu JB, Gerner ST, Schellinger PD, Glahn J, Endres M, Sobesky J, et al. Anticoagulant reversal, blood pressure levels, and anticoagulant resumption in patients with anticoagulationrelated intracerebral hemorrhage. JAMA. 2015;313(8):824-36.

17.• Nielsen PB, Larsen TB, Skjoth F, Lip GY. Outcomes associated with resuming warfarin treatment after hemorrhagic stroke or traumatic intracranial hemorrhage in patients with atrial fibrillation. JAMA Intern Med. 2017;177(4):563-70. A very good long-term follow-up and nationwide observational cohort study showed the benefits of warfarin resumption among patients with $\mathrm{AF}$ and spontaneous hemorrhagic stroke.

18. Murthy SB, Gupta A, Merkler AE, Navi BB, Mandava P, Iadecola $\mathrm{C}$, et al. Restarting anticoagulant therapy after intracranial hemorrhage: a systematic review and meta-analysis. Stroke. 2017;48(6): 1594-600.

19. Poli L, Grassi M, Zedde M, Marcheselli S, Silvestrelli G, Sessa M, et al. Anticoagulants resumption after warfarin-related intracerebral Haemorrhage: the multicenter study on cerebral hemorrhage in Italy (MUCH-Italy). Thromb Haemost. 2018;

20. Park YA, Uhm JS, Pak HN, Lee MH, Joung B. Anticoagulation therapy in atrial fibrillation after intracranial hemorrhage. Heart rhythm: the official journal of the heart rhythm. Society. 2016;13(9):1794-802.

21. Pennlert J, Asplund K, Carlberg B, Wiklund PG, Wisten A, Åsberg $S$, et al. Antithrombotic treatment following intracerebral hemorrhage in patients with and without atrial fibrillation. Stroke. 2015;46(8):2094-9.

22. Yung D, Kapral MK, Asllani E, Fang J, Lee DS, Investigators of the Registry of the Canadian Stroke N. Reinitiation of anticoagulation after warfarin-associated intracranial hemorrhage and mortality risk: the best practice for reinitiating anticoagulation therapy after intracranial bleeding (BRAIN) study. Can J Cardiol. 2012;28(1): 33-9.

23. Paciaroni M, Agnelli G. Should oral anticoagulants be restarted after warfarin-associated cerebral haemorrhage in patients with atrial fibrillation? Thromb Haemost. 2014;111(1):14-8. 
24. Charidimou A, Karayiannis C, Song TJ, Orken DN, Thijs V, Lemmens R, et al. Brain microbleeds, anticoagulation, and hemorrhage risk: meta-analysis in stroke patients with AF. Neurology. 2017;89(23):2317-26.

25. DeSimone CV, Graff-Radford J, El-Harasis MA, Rabinstein AA, Asirvatham SJ, Holmes DR Jr. Cerebral amyloid angiopathy: diagnosis, clinical implications, and management strategies in atrial fibrillation. J Am Coll Cardiol. 2017;70(9):1173-82.

26. Poon MT, Fonville AF, Al-Shahi Salman R. Long-term prognosis after intracerebral haemorrhage: systematic review and meta-analysis. J Neurol Neurosurg Psychiatry. 2014;85(6):660-7.

27. Ren Y, Zheng J, Liu X, Li H, You C. Risk factors of rehemorrhage in postoperative patients with spontaneous intracerebral hemorrhage : a case-control study. J Korean Neurosurg Soc. 2018;61(1): 35-41.

28. Tseng $\mathrm{CH}$, Muo $\mathrm{CH}$, Hsu CY, Kao CH. Increased risk of intracerebral hemorrhage among patients with hepatitis $\mathrm{C}$ virus infection. Medicine. 2015;94(46):e2132.

29. Sturgeon JD, Folsom AR, Longstreth WT Jr, Shahar E, Rosamond WD, Cushman M. Risk factors for intracerebral hemorrhage in a pooled prospective study. Stroke. 2007;38(10):2718-25.

30. van Etten ES, Auriel E, Haley KE, Ayres AM, Vashkevich A, Schwab KM, et al. Incidence of symptomatic hemorrhage in patients with lobar microbleeds. Stroke. 2014;45(8):2280-5.

31. Kongbunkiat K, Wilson D, Kasemsap N, Tiamkao S, Jichi F, Palumbo V, et al. Leukoaraiosis, intracerebral hemorrhage, and functional outcome after acute stroke thrombolysis. Neurology. 2017;88(7):638-45.

32. Yamashita T, Koretsune Y, Yang Y, et al. Edoxaban vs. warfarin in East Asian patients with atrial fibrillation - an ENGAGE AF-TIMI 48 subanalysis. Circ J: Off J Jpn Circ Society. 2016;80(4):860-9.

33. Goto S, Zhu J, Liu L, Oh BH, Wojdyla DM, Aylward P, et al. Efficacy and safety of apixaban compared with warfarin for stroke prevention in patients with atrial fibrillation from East Asia: a subanalysis of the Apixaban for Reduction in Stroke and Other Thromboembolic Events in Atrial Fibrillation (ARISTOTLE) Trial. Am Heart J. 2014;168(3):303-9.

34. Wong KS, Hu DY, Oomman A, et al. Rivaroxaban for stroke prevention in East Asian patients from the ROCKET AF trial. Stroke. 2014;45(6):1739-47.

35. Hori M, Connolly SJ, Zhu J, Liu LS, Lau CP, Pais P, et al. Dabigatran versus warfarin: effects on ischemic and hemorrhagic strokes and bleeding in Asians and non-Asians with atrial fibrillation. Stroke. 2013;44(7):1891-6.

36. Chao TF, Lip GYH, Lin YJ, Chang SL, Lo LW, Hu YF, et al. Major bleeding and intracranial hemorrhage risk prediction in patients with atrial fibrillation: attention to modifiable bleeding risk factors or use of a bleeding risk stratification score? A nationwide cohort study. Int J Cardiol. 2018;254:157-61.

37. Beyth RJ, Quinn LM, Landefeld CS. Prospective evaluation of an index for predicting the risk of major bleeding in outpatients treated with warfarin. Am J Med. 1998;105(2):91-9.

38. Gage BF, Yan Y, Milligan PE, Waterman AD, Culverhouse R, Rich MW, et al. Clinical classification schemes for predicting hemorrhage: results from the National Registry of Atrial Fibrillation (NRAF). Am Heart J. 2006;151(3):713-9.

39. Shireman TI, Mahnken JD, Howard PA, Kresowik TF, Hou Q, Ellerbeck EF. Development of a contemporary bleeding risk model for elderly warfarin recipients. Chest. 2006;130(5):1390-6.

40. Pisters R, Lane DA, Nieuwlaat R, de Vos CB, Crijns HJ, Lip GY. A novel user-friendly score (HAS-BLED) to assess 1-year risk of major bleeding in patients with atrial fibrillation: the Euro Heart Survey. Chest. 2010;138(5):1093-100.

41. De Vleeschouwer S, Van Calenbergh F, van Loon J, Nuttin B, Goffin J, Plets C. Risk analysis of thrombo-embolic and recurrent bleeding events in the management of intracranial haemorrhage due to oral anticoagulation. Acta Chir Belg. 2005;105(3):268-74.

42. Pollack CV Jr, Reilly PA, Weitz JI. Dabigatran reversal with idarucizumab. N Engl J Med. 2017;377(17):1691-2.

43. Gage BF, van Walraven C, Pearce L, Hart RG, Koudstaal PJ, Boode $\mathrm{BS}$, et al. Selecting patients with atrial fibrillation for anticoagulation: stroke risk stratification in patients taking aspirin. Circulation. 2004;110(16):2287-92.

44. Lip GY, Nieuwlaat R, Pisters R, Lane DA, Crijns HJ. Refining clinical risk stratification for predicting stroke and thromboembolism in atrial fibrillation using a novel risk factor-based approach: the euro heart survey on atrial fibrillation. Chest. 2010;137(2):26372.

45. Fang MC, Go AS, Chang Y, Borowsky LH, Pomernacki NK, Udaltsova $\mathrm{N}$, et al. A new risk scheme to predict warfarinassociated hemorrhage: the ATRIA (Anticoagulation and Risk Factors in Atrial Fibrillation) Study. J Am Coll Cardiol. 2011;58(4):395-401.

46. O'Brien EC, Simon DN, Thomas LE, Hylek EM, Gersh BJ, Ansell JE, et al. The ORBIT bleeding score: a simple bedside score to assess bleeding risk in atrial fibrillation. Eur Heart J. 2015;36(46): 3258-64.

47. Apostolakis S, Lane DA, Buller H, Lip GY. Comparison of the CHADS2, CHA2DS2-VASc and HAS-BLED scores for the prediction of clinically relevant bleeding in anticoagulated patients with atrial fibrillation: the AMADEUS trial. Thromb Haemost. 2013;110(5):1074-9.

48. Chan KH, Ka-Kit Leung G, Lau KK, Liu S, Lui WM, Lau CP, et al. Predictive value of the HAS-BLED score for the risk of recurrent intracranial hemorrhage after first spontaneous intracranial hemorrhage. World Neurosurg. 2014;82(1-2):e219-23.

49. Raparelli V, Proietti M, Cangemi R, Lip GY, Lane DA, Basili S. Adherence to oral anticoagulant therapy in patients with atrial fibrillation. Focus on non-vitamin $\mathrm{K}$ antagonist oral anticoagulants. Thromb Haemost. 2017;117(2):209-18.

50. Rivera-Caravaca JM, Roldan V, Esteve-Pastor MA, et al. Cessation of oral anticoagulation is an important risk factor for stroke and mortality in atrial fibrillation patients. Thromb Haemost. 2017;117(7):1448-54.

51. Cannegieter SC, Rosendaal FR, Briet E. Thromboembolic and bleeding complications in patients with mechanical heart valve prostheses. Circulation. 1994;89(2):635-41.

52. Labaf A, Grzymala-Lubanski B, Stagmo M, Lövdahl S, Wieloch M, Själander A, et al. Thromboembolism, major bleeding and mortality in patients with mechanical heart valves - a population-based cohort study. Thromb Res. 2014;134(2):354-9.

53. Ogata T, Yasaka M, Wakugawa Y, Inoue T, Ibayashi S, Okada Y. Deep venous thrombosis after acute intracerebral hemorrhage. J Neurol Sci. 2008;272(1-2):83-6.

54. Pasquini M, Charidimou A, van Asch CJ, et al. Variation in restarting antithrombotic drugs at hospital discharge after intracerebral hemorrhage. Stroke. 2014;45(9):2643-8.

55. Larsen TB, Skjoth F, Grove EL, Nielsen PB, Christensen TD. Effectiveness of self-managed oral anticoagulant therapy in patients with recurrent venous thromboembolism. A propensity-matched cohort study. Thromb Haemost. 2016;116(3):524-9.

56. Oudega R, Hoes AW, Moons KG. The Wells rule does not adequately rule out deep venous thrombosis in primary care patients. Ann Intern Med. 2005;143(2):100-7.

57. Wicki J, Perneger TV, Junod AF, Bounameaux H, Perrier A. Assessing clinical probability of pulmonary embolism in the emergency ward: a simple score. Arch Intern Med. 2001;161(1):92-7.

58. Biffi A, Kuramatsu JB, Leasure A, Kamel H, Kourkoulis C, Schwab K, et al. Oral anticoagulation and functional outcome after intracerebral hemorrhage. Ann Neurol. 2017;82(5):755-65. 
59. Aguilar MI, Hart RG, Kase CS, Freeman WD, Hoeben BJ, García $\mathrm{RC}$, et al. Treatment of warfarin-associated intracerebral hemorrhage: literature review and expert opinion. Mayo Clin Proc. 2007;82(1):82-92.

60. Maeda K, Koga M, Okada Y, Kimura K, Yamagami H, Okuda S, et al. Nationwide survey of neuro-specialists' opinions on anticoagulant therapy after intracerebral hemorrhage in patients with atrial fibrillation. J Neurol Sci. 2012;312(1-2):82-5.

61. Ruff CT, Giugliano RP, Braunwald E, Hoffman EB, Deenadayalu $\mathrm{N}$, Ezekowitz MD, et al. Comparison of the efficacy and safety of new oral anticoagulants with warfarin in patients with atrial fibrillation: a meta-analysis of randomised trials. Lancet (London, England). 2014;383(9921):955-62.

62. Chandra D, Gupta A, Grover V, Kumar Gupta V. When should you restart anticoagulation in patients who suffer an intracranial bleed who also have a prosthetic valve? Interact Cardiovasc Thorac Surg. 2013;16(4):520-3.

63. Becattini C, Sembolini A, Paciaroni M. Resuming anticoagulant therapy after intracerebral bleeding. Vasc Pharmacol. 2016;84:1524.

64. Macellari F, Paciaroni M, Agnelli G, Caso V. Neuroimaging in intracerebral hemorrhage. Stroke. 2014;45(3):903-8.

65. Lip GYH, Collet JP, de Caterina R, Fauchier L, Lane DA, Larsen $\mathrm{TB}$, et al. Antithrombotic therapy in atrial fibrillation associated with valvular heart disease: executive summary of a joint consensus document from the European Heart Rhythm Association (EHRA) and European Society of Cardiology Working Group on Thrombosis, endorsed by the ESC Working Group on Valvular Heart Disease, Cardiac Arrhythmia Society of Southern Africa (CASSA), Heart Rhythm Society (HRS), Asia Pacific Heart Rhythm Society (APHRS), South African Heart (SA Heart) Association and Sociedad Latinoamericana de Estimulacion Cardiaca y Electrofisiologia (SOLEACE). Thromb Haemost. 2017;117(12):2215-36.

66. Hart RG, Pearce LA, Aguilar MI. Adjusted-dose warfarin versus aspirin for preventing stroke in patients with atrial fibrillation. Ann Intern Med. 2007;147(8):590-2.

67. Chatterjee S, Sardar P, Biondi-Zoccai G, Kumbhani DJ. New oral anticoagulants and the risk of intracranial hemorrhage: traditional and Bayesian meta-analysis and mixed treatment comparison of randomized trials of new oral anticoagulants in atrial fibrillation. JAMA Neurol. 2013;70(12):1486-90.

68. Hagii J, Tomita H, Metoki N, Saito S, Shiroto H, Hitomi H, et al. Characteristics of intracerebral hemorrhage during rivaroxaban treatment: comparison with those during warfarin. Stroke. 2014;45(9):2805-7.
69. Inohara T, Xian Y, Liang L, Matsouaka RA, Saver JL, Smith EE, et al. Association of intracerebral hemorrhage among patients taking non-vitamin $\mathrm{K}$ antagonist vs vitamin $\mathrm{K}$ antagonist oral anticoagulants with in-hospital mortality. JAMA. 2018;319(5):463-73.

70. Akin M, Schafer A, Akin I, Widder J, Brehm M. Use of new oral anticoagulants in the treatment of venous thromboembolism and thrombotic prophylaxis. Cardiovasc Hematol Disord Drug Targets. 2015;15(2):92-6.

71. Hirschl M, Kundi M. New oral anticoagulants in the treatment of acute venous thromboembolism - a systematic review with indirect comparisons. Vasa. 2014;43(5):353-64.

72. Lyon C, Mathern S, Devitt J, DeSanto K. Rivaroxaban vs. warfarin for treatment of DVT and PE. Am Fam Physician. 2017;96(8):5323.

73. Schulman S, Ageno W, Konstantinides SV. Venous thromboembolism: past, present and future. Thromb Haemost. 2017;117(7): 1219-29.

74. Sindet-Pedersen C, Langtved Pallisgaard J, Staerk L, Gerds TA, Fosbøl EL, Torp-Pedersen C, et al. Comparative safety and effectiveness of rivaroxaban versus VKAs in patients with venous thromboembolism. A Danish nationwide registry-based study. Thromb Haemost. 2017;117(6):1182-91.

75. Di Nisio M, Vedovati MC, Riera-Mestre A, et al. Treatment of venous thromboembolism with rivaroxaban in relation to body weight. A sub-analysis of the EINSTEIN DVT/PE studies. Thromb Haemost. 2016;116(4):739-46.

76. Orken DN, Kenangil G, Ozkurt H, Guner C, Gundogdu L, Basak $\mathrm{M}$, et al. Prevention of deep venous thrombosis and pulmonary embolism in patients with acute intracerebral hemorrhage. Neurologist. 2009;15(6):329-31.

77. Lip GYH, Lane DA. Matching the NOAC to the patient: remember the modifiable bleeding risk factors. J Am Coll Cardiol. 2015;66(21):2282-4.

78. Horstmann S, Zugck C, Krumsdorf U, Rizos T, Rauch G, Geis N, et al. Left atrial appendage occlusion in atrial fibrillation after intracranial hemorrhage. Neurology. 2014;82(2):135-8.

79. Lane DA, Lip GY. Anticoagulation intensity for elderly atrial fibrillation patients: should we use a conventional INR target (2.0 to 3.0) or a lower range? Thromb Haemost. 2010;103(2):254-6.

80. van Nieuwenhuizen KM, van der Worp HB, Algra A, et al. Apixaban versus Antiplatelet drugs or no antithrombotic drugs after anticoagulation-associated intraCerebral HaEmorrhage in patients with Atrial Fibrillation (APACHE-AF): study protocol for a randomised controlled trial. Trials. 2015;16:393.

81. Start or Stop Anticoagulants Randomised Trial (SoSTART) [https:// clinicaltrials.gov/ct2/show/NCT03153150]. 